\title{
30- Somut olmayan kültürel mirasın elektronik kültür ortamında aktarımı: Kukuli müziklerindeki kültürel unsurlar
}

\section{Şule GÜMÜŞ1}

APA: Gümüs, Ş. (2022). Somut olmayan kültürel mirasın elektronik kültür ortamında aktarımı: Kukuli müziklerindeki kültürel unsurlar. RumeliDE Dil ve Edebiyat Araştırmaları Dergisi, (26), 492-505. DOI: 10.29000/rumelide.1073962.

\section{$\ddot{O} \mathbf{z}$}

Kültür, milletlerin kimliğini belirleyen temel unsurdur. Maddi manevi üretimlerin bütünü olarak değerlendirilen kültür, bir milletin millî kimliğini oluşturduğu için o milletin tarih sahnesindeki varlığını sürdürebilmesi, kültürünü gelecek kuşaklara aktarabilmesi ile doğru orantılıdır. Somut olmayan kültürel mirasın yinelenerek yahut yenilenerek aktarımı çeşitli araçlarla gerçekleşebilmektedir. Bu araçlardan biri de kültür aktarımının en alt tabakasında ve ilk aşamasında bulunan çocuklara hitap eden çizgi filmlerdir. Bu çalışmada Kukuli adlı çizgi filmde yer alan yirmi parçanın içeriği ve klipleri somut olmayan kültürel mirası aktarmadaki rolü açısından incelenmiştir. Çizgi filmin içeriğine uygun olarak yerleştirilmiş olan şarkılar / türküler ile bunların kliplerinde yer alan kültürel unsurlar tespit edilmiştir. Çalışmada örneklem ve içerik analizi yöntemi kullanılmıştır. Yapılan inceleme neticesinde ele alınan şarkılarda ve onların kliplerinde kültürün en temel unsuru olan dile ait kalıp sözlerin, atasözü ve deyimlerin, sıklıkla kullanıldığı tespit edilmiştir. Ayrıca halk oyunları, müzik kültürü, halk mutfă̆ı, halk hekimliği, temizlik, aile kültürü, komşuluk kültürü, paylaşımcllı, meslek folkloru, pazar kültürü tespit edilen kültürel unsurlar arasındadır. Somut olmayan kültürel miras değerlerini etkileyen, modern çağın getirdiği dijital kültür ve şehirlileşme/kültür değişimi gibi konular da incelenen şarkı ve kliplerde yer almaktadır. Kültürel unsurları içeren yerli çizgi filmlerin artması ve bunların uluslararası sunumu kültürümüze ait unsurların yurt içinde ve yurt dışında etkin bir biçimde aktarımını sağlayacaktır.

Anahtar kelimeler: kültür aktarımı, kültürel kod, kültürel miras, çizgi film

\section{The transfer of intangible cultural heritage in digital media: cultural elements in Kukuli songs}

\footnotetext{
Abstract

Culture is the fundamental element that determines the identity of nations. Considered the whole material and moral productions, culture creates the national identity of a nation, so the survival of the nation on the history stage is directly related to its ability to transfer its culture to future generations. The transfer of intangible cultural heritage by repetition or renewal can be achieved through various means. One of these means is cartoons that appeal to children at the lowest level and the first stage of cultural transfer. In this study, the content and video clips of twenty songs in the cartoon Kukuli were examined in terms of their role in transferring the intangible cultural heritage. The songs used according to the content of the cartoon and the cultural elements in the video clips of these songs were determined. The sampling and content analysis methods were used in the study. Nineteen songs with cultural elements were evaluated along with their video clips. As a result of the

Dr. Öğr. Üyesi, Sivas Cumhuriyet Üniversitesi, Edebiyat Fakültesi, Türk Halkbilimi Bölümü, Gösteri Sanatları (Sivas, Türkiye), sulegezer45@gmail.com, ORCID ID: oooo-0001-7028-6292 [Araştırma makalesi, Makale kayıt tarihi: 09.01.2022-kabul tarihi: 20.02.2022; DOI: 10.29000/rumelide.1073962]

Adres $\mid$ Address

RumeliDE Dil ve Edebiyat Araştırmaları Dergisi Osmanağa Mahallesi, Mürver Çiçeği Sokak, No:14/8 Kadıköy - İSTANBUL / TÜRKIYE 34714 e-posta: editor@rumelide.com

RumeliDE Journal of Language and Literature Studies Osmanağa Mahallesi, Mürver Çiçeği Sokak, No:14/8 Kadıköy - ISTANBUL / TURKEY 34714

e-mail: editor@rumelide.com, tel: +90 5057958124, +902167730616 phone: +90 5057958124, +90 2167730616
} 
examination, it was determined that expressions, proverbs, and idioms, the most fundamental element of culture, are frequently used in the songs and their clips. In addition, folk dances, music culture, traditional cuisine, traditional medicine, cleaning, family culture, neighborhood culture, sharing, Professional folklore, market culture are among the cultural elements that were determined. Topics such as affecting intangible cultural heritage values dijital culture and urbanization/culture change brought by the modern age were also found in the songs and clips examined. The increase in domestic cartoons containing cultural elements and their international presentation will ensure that the elements of our culture are effectively transferred at home and abroad.

Keywords: cultural transfer, cultural code, cultural heritage, cartoons

\section{Giriş}

Kültür, bir milletin maddî ve manevi üretimlerinin bütünüdür. Milletlerin millî karakterini oluşturan, bir milletin tarih sahnesindeki duruşunu belirleyen içinde yaşadığı kültürdür. Kültürel benliğini yitiren milletler, asimile olmaya ve varlıklarını kaybetmeye mahkûmdur. Bu sebeple özbenliği meydana getiren kültürel kodların zamana ve zemine uyumlu bir biçimde yinelenerek veya yenilenerek aktarılması gerekmektedir.

Somut olmayan kültürel mirasın korunması ve gelecek kuşaklara aktarımı hususunda uluslararası geçerliliği olan UNESCO Somut Olmayan Kültürel Miras Sözleşmesi vardır. UNESCO'nun 17 Ekim 2003 tarihinde toplanan 32. Genel Konferansı'nda kabul edilen sözleşmede yer alan birinci maddede somut olmayan kültürel miras başlığı altında nelerin bulunduğu ifade edilmektedir (Oğuz, 2009: 63; Oğuz, 2013: 5-13). Buna göre sözlü anlatımlar ve sözlü gelenekler, gösteri sanatları, toplumsal uygulamalar, ritüeller ve festivaller, halk bilgisi, evren ve doğa ile ilgili uygulamalar, el sanatları geleneği somut olmayan kültürel miras unsurları içerisinde değerlendirilmektedir. UNESCO'nun hazırladığı Somut Olmayan Kültürel Mirasın Korunması Sözleşmesi, sanayileşme ve küreselleşme neticesinde zamanla yok olan somut olmayan kültürel miras ürünlerini koruma altına alma düşüncesiyle imzalanmıştır. Türkiye bu sözleşmeye 2006 yllında taraf olmuştur. Sözleşme sürecinde taraf olan devletler ulusal dökümler hazırlayarak Acil Koruma Gerektiren Liste ve Temsili Liste oluşturmuşlardır. Bazı taraf ülkeler ise Yaşayan İnsan Hazineleri Programını ilan etmişlerdir (Gürçayır 2011: 5-10).

Bu sözleşme küreselleşen dünya karşısında yerel kültürleri ve kültürel ifade çeşitliliğini koruma altına almayı hedeflemektedir. Bu hususta müzeleme bir yöntemdir. Bir başka yöntem ise yaşayarak ve yaşatarak korumaktır ki bu da ancak kültür aktarımı ile mümkündür. Kültür aktarımının sağlanacağı araçlardan birisi de çizgi filmlerdir.

Kültür unsurlarının içeriğe uygun bir şekilde çizgi film kurgusuyla aktarılması kültürel belleğin devamlılığını ve kalıcılığını sağlamaktadır. Batı bu hususta çizgi filmlerin etki gücünden oldukça aktif bir şekilde yararlanmaktadır. Giyim kuşamdan yeme içme kültürüne ve aile içi ilişkilerden sosyal iletişime pek çok kültürel değerin Avrupa yapımı çizgi filmlerde yer bulduğu görülmektedir. Günümüzde kültür aktarımı için uygun içeriğe sahip yerli yapım çizgi filmlerin sayısının artması sevindirici bir gelişmedir.

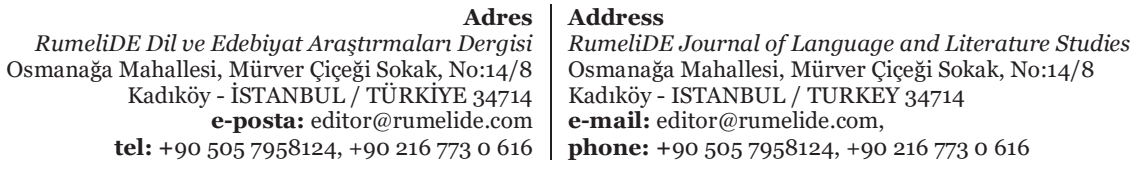

tel: $+905057958124+902167730616$ 
Çizgi filmlerin² hitap ettiği kitle ve etkileme gücü düşünüldüğünde güçlü kodlamalara sahip olduğu görülmektedir. Bu kodlamaların önemli bir kısmı kültür eksenlidir ve gelenekten beslenmektedir. Görsel materyaller sözlü kültürün aktarımı için bir araçtır ve halkbilimcilere araştırma için pek çok malzeme sunmaktadır (Ölçer Özünel, 2012 172). Kültürel kodlar görsel metinler aracılı̆̆ıyla çağa uygun bir biçimde yeni görünümleriyle gelecek kuşaklara aktarılmaktadır (Metin Basat, 2014: 226).

Televizyon çağdaş toplumlarda toplumsal gerçekliği inşa eden bir araçtır (Gerbner, 1972: 37'den aktaran Erdoğan, 2014: 154). Yakın zamana kadar bireyler arası veya grup ilişkileri aracılığıyla yüz yüze gerçekleştirilen kültür aktarımı günümüzde dijital ortamda televizyon ve internet aracıllğı ile sağlanmaktadır. Televizyon ve internetin kültür aktarımına ve devamlılı̆̆ına, düşüncelerin değişim ve dönüşümüne, sosyal hayatta kapladığı yere bakıldığında bu alanda bir araştırma yapma gerekliliği doğmaktadır. TÜİK ve RTÜK'ün 2013 yllında gerçekleştirdikleri araştırmaya göre 6-10 yaş grubu içerisindeki çocukların \% 94,8'inin günlük televizyon izlediği ve bu çocukların \%93,8'inin çizgi film izlediği tespit edilmiştir (Eşitti, 2016: 127). Bu araştırmadan hareketle kültür aktarımının ilk basamağında yer alan çocukların neredeyse tamamının bilincini, kişiliğini şekillendirmede çizgi filmlerin oldukça etkili olduğu ortaya çıkmaktadır. Çizgi filmler, somut olmayan kültürel mirasın aktarımı hususunda da etkin bir araçtır. Yapılan araştırmalar göstermiştir ki çocuklar izledikleri çizgi filmlerden büyük ölçüde etkilenmiş, çizgi film kahramanları gibi davranmaya, giyinmeye özenmişlerdir. 3

\section{Kukuli hakkında}

Kukuli adlı çizgi film, adını çizgi filmin ana karakteri olan maymun Kukuli'den alır. ${ }^{4}$ Çizgi film Kukuli adlı Youtube kanalında, TRT Çocuk ve Minika Çocuk'ta yayınlanmıştır. Yeni bölümleri Youtube kanalında ve Minika Çocuk'ta yayımlanmaya devam etmektedir. Fauna Production'un yapımcılı̆̆ını yaptığı bir yerli çizgi film olan Kukuli'de başkarakter sevimli maymun Kukuli'dir. Tinky ve Minky de kurgu içerisinde öne çıkan diğer iki karakterdir. Bu üçlü dışında Toriki ve Dütdüt de çizgi filmde yer alan karakterlerdir. Kukuli'de her bölüm birbirinden bağımsızdır. Her bölümde farklı bir konu ele alınır. Paylaşma, temizlik, mevsimler, aile içi ilişkiler gibi konular didaktik bir şekilde işlenir. Çocuklara verilmek istenen mesajlar, kurgu içerisine müzik ve dans da eklenerek eğlenceli bir şekilde sunulmaktadır. Çizgi filmin didaktik yönü ağır basmakla birlikte dans ve müzik eşliğindeki sunum, bilgi ve kültür aktarımını ilgi çekici hale getirmektedir.

Kukuli markalaşmış çizgi karakteri ve sosyal medya fenomeni olması bakımından da ilgi çekicidir. 175 çeşit lisanslı ürün ile pazarlama sektöründe de öne çımaktadır. Kukuli filminin kahramanları; oyuncak, kırtasiye ve tekstil sektöründe yerini almıştır. Bu kahramanların resimlerinin olduğu kullanım eşyaları çocuklar tarafından sevilmekte ve tercih edilmektedir. Çok sevilen Kukuli yurt içinde kazandığı başarıyı yurt dışında yayınlanarak uluslararası seviyeye ulaştırmıştır. Çizgi film, İngilizce olarak da piyasada yer almaktadır. Ayrıca 13 farklı dile çevrilmesi hedeflenen film bugün yurt dışında yayımlanma imkânı da bulmuştur. Yerli yapım bir çizgi filmin yurt dışında da gösterime girmesi Türk kültürünün uluslararası tanıtımı noktasında önem taşımaktadır.

Cizgi film ve animasyon kavramları, kavramların tarihçesi ve yapımı hakkında detaylı bilgi edinmek için; Kaba (1992), Atan (1995), Alan (2009), Özakçaoğlu (2009) ve Yapıcıŏ̆lu (2010)'un çalışmalarına müracaat edilebilir.

Konu hakkında detaylı bilgi için bakını: Kaba (1992), Muratoğlu (2009), Atan (1995), Aşçıı (2006), Alan (2009), Eskandari (2007), Kılcı (2009), Özsevgeç ve Saka (2018).

Ayrıntılı bilgi için bakınız: (http://www.animasyongastesi.com/tag/kukuli/) (05.01.2022) ve

(http://www.ranini.tv/haber/31721/1/yerli-cizgi-dizi-kukulinin-sohreti-gunden-gune-buyumeye-devam-ediyor) (05.02.2022).

RumeliDE Dil ve Edebiyat Araşttrmaları Dergisi Osmanağa Mahallesi, Mürver Çiçeği Sokak, No:14/8 Kadıköy - İSTANBUL / TÜRKIYE 34714 e-posta: editor@rumelide.com tel: +90 $5057958124,+902167730616$ 


\section{Kültürden ekrana yansıyanlar: : Kukuli şarkılarındaki kültürel unsurlar}

Bu çalışmada Kukuli adlı çizgi filmde yer alan şarkıların kültür kodlarını aktarma konusundaki rolü değerlendirilmiştir. Çizgi filmde yer alan şarkılar ve bu şarkıların kliplerinde yer alan kültürel unsurlar tespit edilmiştir. Çalışmada örneklem ve içerik analizi yöntemi kullanılmıştır. İçerisinde kültürel unsurları barındıran yirmi şarkı, klipleri ile birlikte değerlendirilmeye tabi tutulmuştur. Buna göre şarkılarda ve kliplerinde sözlü kültürümüzün önemli bir parçası olan deyimlere sıklıkla yer verildiği görülmektedir. Bunun yanında halk oyunları, müzik kültürü, halk mutfağı, halk hekimliği, temizlik, aile kültürü, komşuluk kültürü, paylaşımcılık, meslek folkloru, pazar kültürü tespit edilen kültürel unsurlar arasındadır. Modern çağın getirdiği dijital kültür ve şehirlileşme/kültür değişimi gibi konular da incelenen şarkı15 ve kliplerde yer almaktadır.

\subsection{Kalıp sözler}

Kültür oluşumunu, gelişimini ve gelecek nesillere aktarılmasını sağlayan dildir. Bu sebeple dile ait değerler kültürün en önemli unsurlarıdır. Bu hususta içeriğinde bir milletin yaşanmışlıklarını ve özbenliğine ait hususları içeren atasözü ve deyimler öne çıkmaktadır. Kukuli adlı çizgi filmin şarkıları incelendiğinde özellikle deyimlerin yoğun olarak kullanıldığı tespit edilmektedir. Elini Yıka adlı şarkıda; tahtalıköyü boylamak, mis gibi kokmak deyimleri yer almaktadır: "Aç musluğu su aksın kir pis pas pus kalmasın / O zalım bakteriler tahtalıköyü boylasın / (...) Sabun mis gibi kokar hem temizler hem paklar / Ylkanınca ellerin oh ne güzel ferahlar.”

Pasaklı, adlı şarkıda; deli etmek, mikrop yuvası deyimleri öne çıkar: "Pasaklı pasaklı / Pasaklısın Kukuli / Kirlettin her yeri / Deli ettin Tinky'i / (...)Hep kirlidir odası / Kokusu da cabası / Tam bir mikrop yuvası." Nereye Koyduysan Ordadır şarkısında ise "altını üstüne getirmek" deyimi dikkat çeker: "Sağa baktım sola baktım bulamadım / Nereye koyduysan ordadır. / Evin altını üstüne getirdim / Nereye koyduysan ordadır." Düt Düt adlı şarkıda, "Dütdüt'tür benim adım / Yollar benden sorulur / Benimle aşık atan / Beş dakikada yorulur / Şimşek gibi çakarım / Rüzgâr gibi geçerim / Şoförlükte ustayım / Gezmeyi çok severim.” sözlerinde geçen "benden sorulur, aşık atmak, şimşek gibi çakmak, rüzgar gibi geçmek" ifadeleri dilimizde kalıplaşmış deyimlerdir.

Tut Tut adlı şarkıda; dişini sıkmak, yolunu tutmak, kendini koyuvermemek deyimleri yer almaktadır: "Çişin geldi tut tut tut ssk dişini Kukuli / Tuvaletin yolunu tut tut tut / (...) Koyverme kendini hemen / Tuvaletin yolunu tut tut tut.” Yaz Geldi adlı şarkıda; kendini dışarı atmak, tadını çıkarmak, kahkaha patlatmak, aşka gelmek deyimleri vardır: "Yaz geldi, okullar tatile girdi / Sonunda, şortlar terlikler giyildi / Kukuli, kendini dışarı attı / Sokakta, yazın tadını çıkardı / (...) Patladı, neşe dolu kahkahalar / Ağaçlar meyveye doydu / Başaklar sapsarı oldu / Sarı kız ikiz doğurdu / Yaz geldi / Kınalı kuzu meledi / Balarısı vız vız dedi / Çiçek böcek aşka geldi.” Ayrıca bu şarkının klibinde havanın sıcaklığını göstermek için Kukuli yere yumurta kırar ve yumurta pişer. Halk arasında yaygın olan ve havanın çok sıcak olduğunu belirtmek için kullanılan 'Kafamda yumurta kırsam pişer.' deyiminin klipte gösterimi gerçekleştirilmiştir. Abur Cubur adlı şarkıda; yazık olmak ve mideyi bozmak deyimleri yer alır: "Karnın ağrır gurul gurul / Sağlığına yazık olur. / (...)Abur cubur hapur hupur / Sonunda bozdun mideyi.”

Paylaşmak Güzel adlı şarkıda hadi yine iyisin, kardeş payı deyimleri yer alır: "Hey Kukuli merhaba! / Nasılsın, iyi misin? / Bir sürprizim var sana hadi yine iyisin! / Çikolata çok tatlı ama paylaşmak daha

Bu makalede kullanılan şarkı / türkü sözleri https://www.youtube.com/watch?v=tıAadJ_jR9c (02.01.2022) adresinde yer alan videolardan alınmıştır.

RumeliDE Dil ve Edebiyat Araştırmalart Dergisi Osmanağa Mahallesi, Mürver Çiçeği Sokak, No:14/8 Kadıköy - İSTANBUL / TÜRKIYE 34714 tel: +90 $5057958124,+902167730616$ 
tatlı / Bir sana bir de bana yapalım kardeş payı / Paylaşmak güzel paylaşmak güzel.” Arkandan Ağlar adlı şarkıda pat diye, boynu bükük, hüzün çökmek, yüzü düşmek, ah çekmek, silip süpürmek, götürmek (yemek) deyimleri tespit edilmektedir: "Bak yine yarım bıraktı. / Pat diye sofradan kalktı. / Nohutlu pilav barbunya. / Boynu bükük mahzun kaldı. / (...) Sofraya bir hüzün çöktü. / Mercimeğin yüzü düştü. / Köfte derin bir ah çekti. / Bak en çok ekmek üzüldü. / Arkandan ağlar, arkandan ağlar. / (...) İyi sıyır sil süpür / Ye bitir hadi götür / Yazık çöpe gitmesin kalanlar.” Akşam Yatmaz Sabah Kalkmaz adlı şarkıda uykusunu almak, seni gidi, büyük sözü dinlemek, geri kalmak ifadeleri kalıp kullanımlar olarak dikkat çekmektedir: "Akşam yatmaz sabah kalkmaz / Uykusunu alamaz / Seni gidi yaramaz / (...)Tam bir haylaz / Saat olmuş 11-12 / Hala ayakta bizimki / Büyük sözü dinlemez ki / Terliği yer annesinden / Geceleri geç yatınca / Sabahları geç kalkınca / Okula da geç kalınca / Geri kalır derslerinden.” Kar Yağıyor adlı şarkıda; sabahın körü, tatlı bir telaş içinde olmak, su gibi akmak, gece gündüz (sürekli), göbek atmak deyimleri yer almaktadır: "Kukuli'ye bakın hele! / Kalkmış sabahın köründe. / (...) Tatlı bir telaş içinde eldivenleri elinde. / (...) Sonbahar, yaz, ilkbahar, kış / Günler su gibi akarmış. / Gece gündüz hep kar yağmış / Vali televizyona çıkmış / Okulları tatil yapmış / Çocuklar çok mutlu olmuş / Mutluluktan göbek atmış."

Hıçkırık adlı şarkıda ise boğazına takılmak ve kâr etmemek deyimleri yer alır: "Takılmış boğazına / Gitmemiş bu hıçkırık / (...) Hiç bir şey kar etmemiş / Geçmemiş bu hıçkırık” Turşu Turşu adlı şarkıda tadına doyamamak ve içinin bir hoş olması deyimleri dikkat çeker: "Doyamam hiç tadına kıtır kıtır dişlerim / Bi' hoş oluyor içim kamaşıyor dişlerim.” Tebessüm En Güzel Hediye adlı şarkıda; çatık kaşlı, atarlı, mahkeme duvarı, ekşi surat, gemileri batmak, yüzünde güller açmak, iki gözüm, yüzü sirke satmak, ömre bedel, afakanların basması, içi kararmak, pişmiş kelle gibi ifadeleri yer alır: "Uyanır çatık kaşlı / Huysuz, aksi atarlı / Hiç bir nedeni yokken / Yüz mahkeme duvarı/ Ekşi suratla gezer sorsan yok bir şeyim der / Gemilerin mi battı? / Kukuli artık yeter / Güller açsın yüzünde / (...) Kukuli iki gözüm/ Sirke satmasın yüzün / Bir gülüş ömre bedel / Sen gülsen dünya güler / Afakanlar basmasın / İçin hiç kararmasın / Tam pişmiş kelle gibi / Haydi sırıt bakalım / Güller açsın yüzünde / Gülümse gülümse.”

Barış Manço'nun "Nane Limon Kabuğu” adlı parçasına da çizgi filmde yer verilmiştir ve bu şarkının sözlerinde çok sayıda kalıplaşmış söz yer almaktadır: "Bir çiçekle bahar olmaz.”, "kendini bilmek", "can pazarı”, "Zürafanın düşkünü beyaz giyer kış günü.”, "şifayı kapmak”, " bin derde deva” " çok yaşa / sen de gör”, “önünü kış tutmak”, "evdeki hesap çarşıya uymaz”, "dizini dövmek”. Şarkının sözlerinde geçen bu kalıp ifadeler dilimizin zenginlikleridir ve bu şarkının çizgi film içerisinde yer alması bu kültürel zenginliklerin çocuklara aktarımını hem kolaylaştırmış hem de akılda kalıcı olmasını sağlayarak hızlandırmıştır. Şarkının sözleri şu şekildedir: "Eski adamlar doğruyu söylemiş / Bir çiçekle bahar olmaz / Kişi kendini bilip sağa sola sormalı / Can pazarı bu oyun olmaz / Zürafanın düşkünü beyaz giyer kış günü / Sonunda şifayı kapıpta şaşırınca / Bana gel beni dinle iyi yaz / Defteri kalemi al iyi yaz / Nane limon kabuğu bir güzel kaynasın aman / Ha ha ha ha ha içine hatmi çiçeği biraz tere otu katasın aman / Ha ha ha ha ha hatta biraz tarçın bir tutam zencefil aman / Ha ha ha ha ha bin derde deva geliyor biraz daha sabret güzelim / Ha ha ha ha ha hapşu / Çok yaşa / Sen de gör / Rahat ve iyi yaşa / Sen tedbirini al önünü kış tut bırak yine de yaz gelsin / Çoğu zaman hesap çarşıya uymaz sonra dizini döversin.”

Dilin soyut anlamlı sözcükleri olan deyim ve atasözlerinin müzik ve dans eşliğinde şarkılar içerisinde sunumu çocukların ilgisini çekmiş ve kültürün temel unsuru olan dile ait aktarımın gerçekleşmesi kolay ve eğlenceli hale gelmiştir.

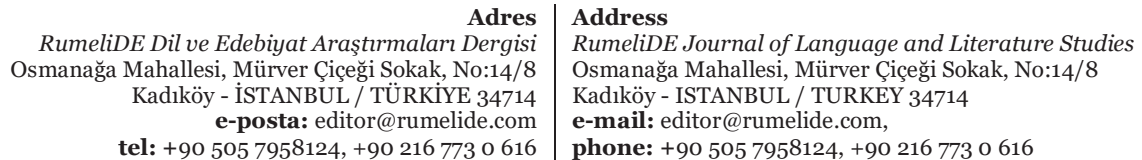
tel: +905057958124

phone: +90 $5057958124,+902167730616$ 


\subsection{Tekerleme}

Çizgi filmde yer alan Macera Diyarı adlı şarkının sözlerinde masal tekerlemesine yer verildiği görülmektedir. Masallarda zamanı hızlandırmak için kullanılan geçiş tekerlemesi şarkıda yer alır: "Macera diyarı macera diyarı / Geliyorum az kaldı az kaldı / Az kaldı / Az gittim ve uz gittim / Dere tepe düz gittim / Yoruldum ama yılmadım / Sonunda yolları tükettim”. Sözlü kültür ürünlerimizden olan masalın önemli bir parçası olan tekerlemelerin çizgi film içerisinde şarkı formatında yer alması, kültür aktarımı açısından önem arz etmektedir.

\subsection{Müzik}

Ele alınan şarkılarda Türk müzik kültürünün hem geleneksel hem de modern örneklerine yer verilmiştir. Ordu yöresine ait olan Fındık Dalları adlı türkü çizgi filmde "Yine yeşillendi findık dalları/Zaten hep yeşildi fındık dalları" sözleriyle yer almıştır. Geleneksel müzik kültürümüzü yansıtan bu örneğin çizgi film içerisindeki sunumu geleneksel müziğin gelecek kuşaklara aktarımı açısından önemlidir. Küçük bir çocuk tek başına türküyü dinlemekten hoşlanmayabilir ancak çizgi film içerisinde yer aldığında bu onun ilgisini çekecektir.

Çizgi filme ait şarkılar bölümünde sadece halk müziğine değil klasik müziğe de yer verilmiştir. "Katibim" veya "Üsküdar’a Gider iken" adıyla bilinen parça ${ }^{6}$ film içerisinde sözsüz olarak yer alır. Klibinde ise Minky'nin gitar çaldığı görülürken Tinky elinde kenarları işlemeli, pembe bir şemsiyeyi döndürür. Bu haliyle Tinky, eski İstanbul hanımefendilerini taklit etmektedir.

"Hayat Hareket" adlı şarkının müziği ise 70’li yılların Türk filmlerinde sıkça görülen kanto müziği andırmaktadır. Geleneksel müzik kültürünün yanı sıra modern müzik kültürümüzün de çizgi film içerisinde yer bulduğu görülür. Barış Manço'ya ait olan iki şarkı ele alınan senaryo ile bağlantılı olarak çizgi film içerisine yerleştirilmiştir. Bunlardan ilki 1981 ylında çıan ve "Sözüm Meclisten Dışarı" adlı albümde yer alan "Arkadaşım Eşek" adlı şarkı, diğeri 1998 ylında çıkan ve "Full Aksesuar 88 Manço Sahibinden İhtiyaçtan" adlı albümde yer alan "Nane Limon Kabuğu" adını taşıyan şarkıdır. Ayrıca Mahmut Tuncer'in 1992 yılında çıkan "Kalbimde Sen" adlı albümünde yer alan "Bakkal Amca" adlı şarkı da çizgi filmde yer almaktadır. Bugün nostalji kuşağında yer alan bu şarkıların çizgi film içerisinde çocuklara aktarılması müzik kültürümüze dair birikimin yeni nesillerce bilinmesini sağlayacaktır.

\subsection{Halk dansları}

Dans, duygu ve düşüncenin, yașam tarzının müzik eșliğinde beden hareketleriyle aktarımıdır. Bir milletin yerel dansları incelendiğinde kültürel yaşamı ile ilgili ipuçlarına ulaşmak mümkündür. Halk dansları içinden çıktığı toplumun sosyal ve ekonomik durumunu, coğrafya ve iklimini, geçim kaynaklarını, duygu ve düşünce dünyasını yansıtmaktadır. İncelenen şarkıların kliplerinde Türk halk danslarından örnekler söz konusudur. Kukuli adlı çizgi filmin incelenen şarkılarından dördünün klibinde halk dansları icrası gerçekleştirildiği görülmektedir. Elini Yıka adını taşıyan şarkının klibinde Kukuli elinde marakas7 ile ritim tutar. Tinky ve Minky de çiftetelli oynar.

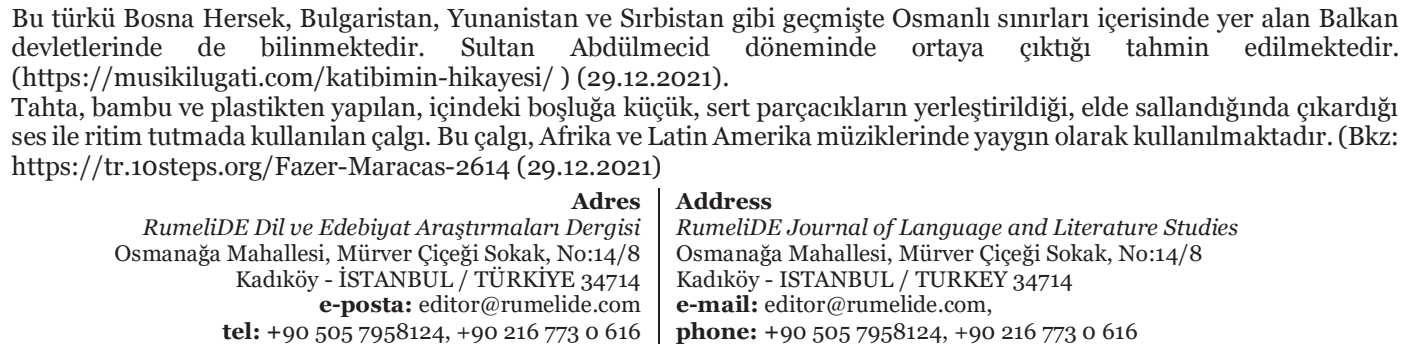
devletlerinde de bilinmektedir. Sultan Abdülmecid döneminde ortaya çıtı̆̆ tahmin edilmektedir. (https://musikilugati.com/katibimin-hikayesi/) (29.12.2021).

Tahta, bambu ve plastikten yapılan, içindeki boşluğa küçük, sert parçacıkların yerleştirildiği, elde sallandığında çıkardığı ses ile ritim tutmada kullanılan çalgı. Bu çalgı, Afrika ve Latin Amerika müziklerinde yaygın olarak kullanılmaktadır. (Bkz: https://tr.10steps.org/Fazer-Maracas-2614 (29.12.2021) 


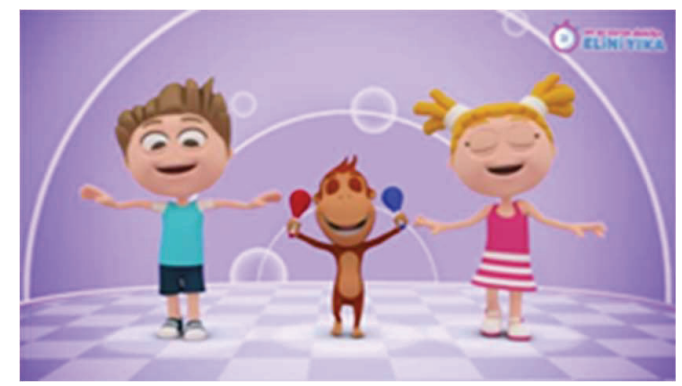

Resim 1: Tinky ve Minky çiftetelli oynarken. (https://www.youtube.com/watch?v=t1AadJ_jRgc) (02.01.2022)

Çizgi filmde yer alan Fındık Dalları adlı türkünün klibinde ise kaşık oyunlarının icrası görülmektedir. Kukuli, Tinky ve Minky ellerinde uzun saplı kaşılarla dans eder.

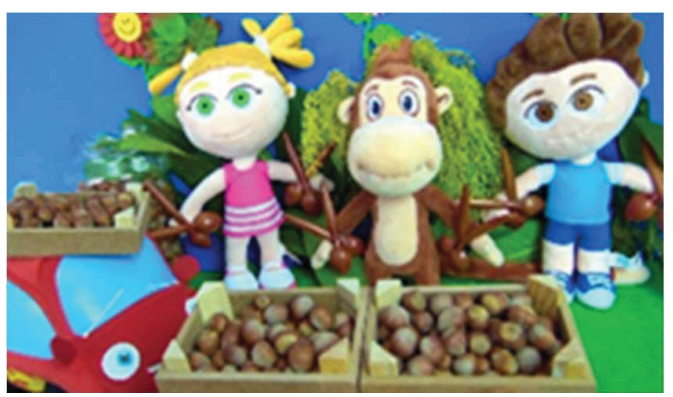

Resim 2: Kukuli, Tinky ve Minky kaşık oyunu oynarken.

(https://www.youtube.com/channel/UCF5IUvgXe_3sHBuKpEz7Btw) (02.01.2022)

Tebessüm En Güzel Hediye adını taşıyan şarkının klibinde ise halk danslarımızdan halayın icrası yer almaktadır. Tinky, Kukuli ve Minky el ele tutuşarak halay kurar. "Hayat Hareket” adlı şarkının klibinde de halay icrası görülmektedir. Önde Tinky, Minky ve Kukuli bir dizi halinde, arkada ev halkı yine dizi halinde ve el ele tutuşarak halay kurar. Arkadaki dizide halay başı Toriki'dir. Her iki şarkının klibinde de koreografik olarak halayın düz dizi halinde ve "yelleme" denilen hızlı/ hareketli bölümünün oynandığı görülmektedir.

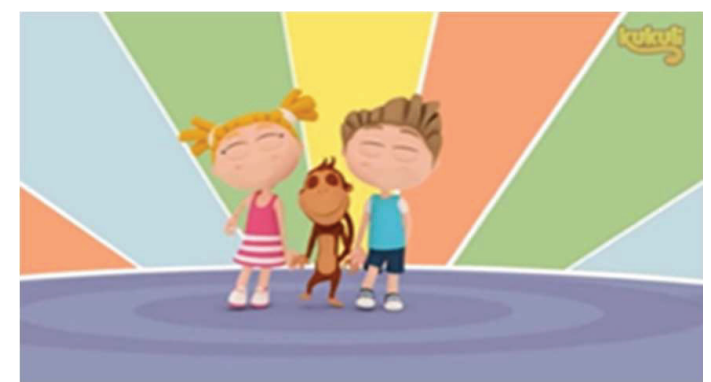

Resim 3: Kukuli, Tinky ve Minky halay çekerken.

(https://www.youtube.com/channel/UCF5IUvgXe_3sHBuKpEz7Btw ) (02.01.2022) 


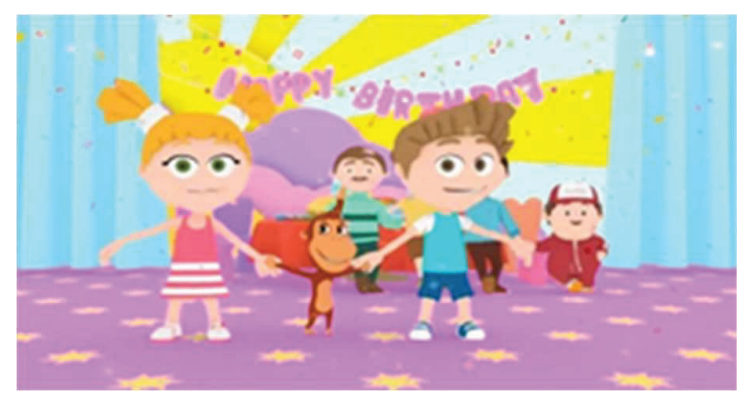

Resim 4: Kukuli, Tinky ve Minky ile evdekiler halay çekerken.

(https://www.youtube.com/channel/UCF5IUvgXe_3sHBuKpEz7Btw ) (02.01.2022)

\subsection{Halk hekimliği}

Halk hekimliğine ${ }^{8}$ yönelik uygulamalar da şarkılarda ele alınmıştır. Günümüzde tıp biliminin yanında alternatif tıp uygulaması olarak varlı̆̆ını sürdüren halk hekimliği, ataların uzun süreli gözlem ve tecrübeleri doğrultusunda ortaya koydukları yöntemlerle doğal yollara başvurarak sağaltmanın gerçekleştirilmesini sağlamaktadır. Halk arasında yaygın olarak bilinen ve soğuk algınlı̆̆ına şifa olarak görülen nane limon, Kukli adlı çizgi filmde yer almıştır. Barış Manço’nun "Nane, Limon Kabuğu” adını taşıyan şarkısı çizgi filmin konusuna uygun olarak film içerisine yerleştirilmiştir.. Şarkının klibinde ise Tinky ve Minky hasta olur, Kukuli onları iyileştirmek için nane limon hazırlar. Şarkı sözlerinde nane limonun nasıl hazırlanacağı anlatılır: "Eski adamlar doğruyu söylemiş / Bir çiçekle bahar olmaz / Kişi kendini bilip sağa sola sormalı / Can pazarı bu oyun olmaz / Zürafanın düşkünü beyaz giyer kış günü / Sonunda şifayı kapıpta şaşırınca / Bana gel beni dinle iyi yaz / Defteri kalemi al iyi yaz / Nane limon kabuğu bir güzel kaynasın aman / Ha ha ha ha ha içine hatmi çiçeği biraz tere otu katasın aman / Ha ha ha ha ha hatta biraz tarçın bir tutam zencefil aman / Ha ha ha ha ha bin derde deva geliyor biraz daha sabret güzelim.” Burada halk hekimliğine ait bu bilginin şarkı formatında aktarımı Barış Manço'nun kültür aktarımına değerli bir katkısı olmuştur. Bu şarkının çizgi film içerisinde yer alması ise bu kültür aktarımının çocuklar arasında daha kolay gerçekleşmesini sağlamıştır. "Hıçkırık" adlı şarkıda da hıçkırık tuttuğunda uygulanan doğal yöntemlere yer verilmektedir. Bu yöntemlerden birisi de maydanoz yemektir: "Neler neler denemiş / Maydanoz bile yemiş / Hiç bir şey kâr etmemiş /Geçmemiş bu hıçkırı." Günlük hayatta işe yarayacak olan halk hekimliğine dair bilgilerin çizgi film içerisindeki sunumu hem kültürel belleğin aktarımını sağlamış hem de günlük yaşam bilgisi kazandırmıştır.

\subsection{Mutfak kültürü ve sofra adabı}

İncelenen şarkılarda Türk mutfak kültürüne9 ve sofra adabına yönelik unsurlar da yer almaktadır. "Arkandan Ağlar”, “Abur Cubur”, "Turşu Turşu”, “Bakkal Amca” adlı şarkılarda Türk mutfağında pişen yemekler, yeme içme kültürü yer almaktadır. "Arkandan Ağlar” adlı şarkının klibinde Kukuli tabağını bitirmeden sofradan kalkar ve bu davranışı yanlış bulunur. Türk sofra adabına göre tabağını bitirmeden kalmak doğru değildir. Şarkının sözlerinde sofradaki yemekler kişileştirilir ve onların bu davranış karşısında üzüldüğü söylenir. Burada sofrada yer alan yemekler hakkında bilgi edinmiş oluruz. Nohutlu pilav, barbunya, mercimek, köfte ve ekmek sofrada yer alan yiyeceklerdir: "Bak yine yarım bıraktı / Pat

$8 \quad$ P. Naili Boratav’a göre halk hekimliğini şekillendiren halkın maddi durum yetersizliği veya başka nedenlerden ötürü doktora gidemediği ya da gitmek istemediği zaman hastalıkları teşhis ve sağaltma amacıyla geliştirdikleri yöntemlerdir. (1997; 122-123)

Mutfak Kültürü: Belenmede kullanılan yiyecek içeceklerle birlikte bunların hazırlanışını, pişirme, saklama ve tüketim usullerini, kullanılan araç gereçleri, yeme içme ile ilgili toplumsal uygulama ve inanışları, mekan olarak mutfağı kapsayan geniş bir içeriğe sahiptir.

RumeliDE Dil ve Edebiyat Araştırmaları Dergisi Osmanağa Mahallesi, Mürver Çiçeği Sokak, No:14/8 Kadıköy - İSTANBUL / TÜRKIYE 34714 tel: $+905057958124+902167730616$
Address

RumeliDE Journal of Language and Literature Studies

Osmanağa Mahallesi, Mürver Çiçeği Sokak, No:14/8

Kadıköy - ISTANBUL / TURKEY 34714

e-mail: editor@rumelide.com

phone: +90 $5057958124,+902167730616$ 
diye sofradan kalktı / Nohutlu pilav, barbunya /Boynu bükük mahzun kaldı / Arkandan ağlar, arkandan ağlar /Arkandan ağlar, tabağında kalanlar / (...) Sofraya bir hüzün çöktü / Mercimeğin yüzü düştü / Köfte derin bir ah çekti / Bak en çok ekmek üzüldü.” Burada en çok ekmeğin üzüldüğünün söylenmesi Türk halk inanışlarında ekmeğe atfedilen kutsiyet ile ilişkili olmalıdır. Ekmek, Türk kültüründe rızık ile ilişkilendirilmiştir ve ekmeğe saygısızlık edilmesinin fakirlik ve bereketsizliğe yol açacağına inanılmıştır. Bu inanış şarkıda ekmeğe yapılan vurgu ile yer almıştır. Ayrıca Türk sofra adabında israf etmek yasaktır, herkes önüne gelen rızkı bitirmelidir. Yemeklerin çöpe gitmesi "yazık olması" demektir ve bu eve fakirlik gelmesine neden olmaktadır. Şarkıda yer alan "(...) İyi sıyır sil süpür / Ye bitir hadi götür /Yazık çöpe gitmesin kalanlar.” sözleriyle adeta bu inanışa vurgu yapılmıştır.

"Abur Cubur" adlı şarkıda da Türk kültüründeki yeme içme alışkanlıklarına dair bilgilere rastlanmaktadır. Şarkıda geçen “"Ben günde üç öğün yemeğimi yerim / Sağllklı beslenmeye dikkat ederim" ifadeleri Türk beslenme kültüründe üç ögünün bulunduğunu ve doğal beslenmenin önem arz ettiğini göstermektedir. Sağlıklı beslenme için tercih edilen besinler ise şöyle sıralanır: "Et, patates, salata, fasulye, balık, pırasa/ Yemek seçmem asla her şeyi yerim.” Burada yemek seçmeme sağlıklı beslenmenin anahtarı olarak yer alır, aynı zamanda bu, bir sofra adabıdır. Türk sofra adabına göre kişi sofradaki yemeği beğenmemezlik yapmamalıdır. Yemek seçmek, yemekleri beğenmemek; rızkı küçümsemek anlamına geldiği için bereketsizlik getirecektir. Üstelik kişi misafirlikte ise ev sahibini de kırmış olur. Bu sebeple yemek seçmek doğru bulunmaz. Şarkının devamında üç öğünde hangi yiyeceklerin tüketildiğine dair bilgiler de yer almaktadır. Tinky ve Minky; kahvaltıda süt ve yumurta, öğlen sebze yemeği, akşama ise çorba, tavuk ve makarna yediğini söylemektedir: "Kahvaltıda yumurta, sütümü içerim / Öğlenleyin mutlaka sebzemi yerim / Akşama da çorba, tavuk, makarna / Yemek seçmem asla her şeyi yerim.” Bu şarkı aracılığıyla Türk beslenme kültürü bir yönüyle tanıtılmıştır. Bu kültürün içerisinde abur cubura çok yer yoktur. Şarkıda geçen: "Abur cubur abur cubur/ Oburluğun sonu budur / Karnın ağrır gurul gurul / Sağlığına yazık olur / Ah Kukuli vah Kukuli / Niye yedin onca şeyi / Abur cubur hapur hupur / Sonunda bozdun mideyi." ifadelerinde abur cubur yemenin sağlıksız olduğu söylenmiş ve düzensiz beslenme eleştirilmiştir.

"Turşu Turşu” adlı şarkıda ise Türk mutfak kültürünün önemli besinlerinden olan turşular hakkında bilgi verilmiştir. Turşu kurmak kış hazırlıkları arasında önemsenmektedir. Bilindiği gibi turşu suyu kışın soğuk günlerinde sokak satıcıları tarafından satılmakta ve halk buna rağbet etmektedir. Turşunun nasıl kurulduğunu ve Türk beslenme kültüründe hangi turşuların olduğunu şarkının sözlerinden anlamak mümkündür. Şarkıda geçen turşular şunlardır: "Erik turşusu, biber turşusu / Kekik turşusu, kelek turşusu / Kornişonu, havucu çok lezzetli doğrusu / Ama benim favorim salatalık turşusu / Fasulye, domates, kelem, turşusu / Brokoli, karnabahar turşusu." Ayrıca şarkının girişinde yer alan "Hadi gel gidelim pazara komşu / Alalım lahana kuralım turşu.” İfadelerinde de lahana turşusu geçmektedir. Turşunun sadece kendisi yenmemekte suyu da içilmektedir: "Gel otur yanıma yiyelim turşu/ Sonra da suyunu içelim komşu." ifadelerinde Türk beslenme kültüründe yer alan bu uygulama tespit edilmektedir. Şarkıda turşunun kuruluşu hakkında da bilgi verilmektedir: "Doldur doldur tepeleme tepeleme / Bol bol limon bol bol sirke / Bastır bastır sıkı sıkı sıkı sıkı / Kapağını kapat vıcı vıcı vıcı vıcı / Hazır olsun bu kışa / Fıçı fıçı fıçı fıçı / Turşuuuuuu". Şarkının klibinde de Kukuli, Tinky ve Minky önce pazara gidip turşuluk malzeme alır, sonra evde turşu kurar. Böylece Türk mutfak kültürüne ait bir yiyeceğin yapılış aşamaları ayrıntılı olarak gösterilmiş olur.

Çizgi filmde yer alan "Bakkal Amca" adlı şarkıda da Türk beslenme kültüründe öne çıkan helva ve mangal yer almaktadır. Helvanın yağ, un ve şeker ile yapıldığı da yine şarkının sözlerinden anlaşılmaktadır: "Bakkal amca! / Ne var? / Yağın var mı? / Var var / Unun var mı? / Var var / Şekerin

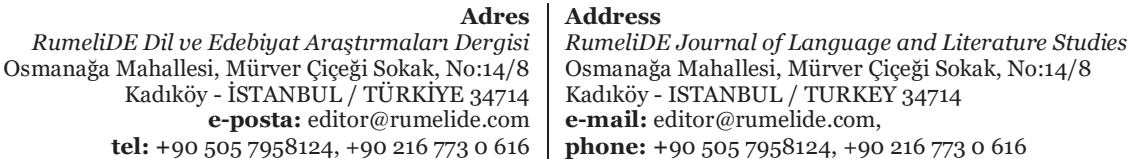


var mı? / Var var / Ne duruyorsun? / Ne yapayım? / Helva yapsana!” Şarkının klibinde de bakkal amca helva yapar Kukuli, Tinky, Minky, Toriki yer. Şarkıda geçen "Kasap amca! / Ne var? / Pirzolan var mı? / Var var / Izgaran var mı? / Var var / Kömürün var mı? / Var var / Ne duruyorsun? / Ne yapayım? / Mangal yapsana!” sözleri de mangal kültürünü yansıtmaktadır. Klipte kasap amca mangal yakar. Kukuli de mangal yakıp muz közler.

Görüldüğü gibi incelenen şarkılarda Türk beslenme kültüründe öne çıkan yiyecekler, bu yiyeceklerin nasıl hazırlandığı ve sofra adabına dair hususlar yer almaktadır. Kültürün önemli bir parçası olan beslenme kültürüne dair hususların çizgi filmde şarkı formatında aktarımı geleneksel beslenme kültürünün benimsenmesi ve devamlılı̆̆ı için önemlidir.

\subsection{Temizlik}

Türk kültüründe temizlik, temiz olmak temel davranışlar arasında yer alır. "Evini temiz tut, misafir gelir; bedenini temiz tut ölüm gelir." "Temizlik, imandandır” gibi sözler Türk kültüründe temiz olmaya verilen önemi ortaya koymaktadır. Kukuli adlı çizgi filmde de temiz olma, vücudunu temiz tutma hususları teşvik edilmektedir. "En Az Yarım Dakika Elini Yıka", "Dişlerimi Fırçalarım" ve "Pasaklı" şarkılarında çocuklara temiz olma özendirilmektedir. "Elini Yıka" adlı şarkıda kişinin sokaktan gelince, yemeklerden önce, öksürünce, hapşurunca ellerini sabun ve bol su ile yıkaması tavsiye edilir: "Ellerin kirlenince koş hemen lavaboya / Köpürt köpürt sabunla mikropları kovala / En az yarım dakika elini yıka / Aç musluğu su aksın kir pis pas pus kalmasın / O zalım bakteriler tahtalıköyü boylasın / (...) Sabun mis gibi kokar hem temizler hem paklar / Ylkanınca ellerin oh ne güzel ferahlar / (...)Köpürt köpürt sabunla elini yıka / Vıcı vıcı durula elini yıka / Kukuli hadi ama elini yıka / Sakın bunu unutma elini yıka / Sokaktan dönünce elini yıka / Yemeklerden önce elini yıka / Öksürünce hapşırınca elini yıka / Aksırınca tıksırınca elini yıka."

"Dişlerimi Fırçalarım" şarkısında ise yemeği bitirince ve yatmaya gitmeden önce günde iki kez dişlerin fırçalanması gerektiği söylenmektedir: "Yemeğimi bitirince dişlerimi firçalarım / Yatmaya gitmeden önce dişlerimi firçalarım / Bembeyaz bütün dişlerim onlara iyi bakarım / Günde iki kez mutlaka dişlerimi firçalarım." Şarkıda dişlerin nasıl firçalanacağı da anlatılır ve klibinde Kukuli, Tinky ve Minky tarafından gösterimi yapılır: "Bir sağa bir sola çalkala çalkala / Yukarıya aşağıya gargara gargara."

"Pasaklı" adlı şarkıda ise Kukuli özelinde pasaklı kişileri kimsenin sevmeyeceği ve bu kişilerin toplum tarafından dışlanacağı ifade edilir: "Çamurlu ayakları, uzamış tırnakları / Yıkamaz hiç yüzünü, gözleri hep çapaklı / Pasaklı, pasaklı, pasaklısın Kukuli / Kirlettin her yeri, deli ettin Tinky'i / Dağınıktır masası, hep kirlidir odası / Kokusu da cabası, tam bir mikrop yuvası." Şarkının sonunda "Temizlik güzeldir, mutlu eder herkesi /Pasaklı olup da üzmeyin annenizi.” ifadeleriyle temizlik teşvik edilmektedir.

\subsection{Komşuluk kültürü}

Türk kültürünün önemli değerlerinden biri olan "komşuluk" toplumsal hayatın temel dinamiklerindendir. Türk toplum yapısının güçlü kalmasını sağlayan unsurların başında yer alan komşuluk kültürü köklü bir tarihî geçmişe sahiptir (Ahunbay vd. 2018). Günlük hayatta her zaman iç içe olunan komşular aile bireyleri kadar yakın kabul edilmiş; yeri geldiğinde mal mülk hatta eş, evlat komşuya emanet edilmiştir. Acılar, sevinçler komşu ile paylaşılmış; en güvenilir dost olarak komşu kabul görmüştür. Dayanışma, yardımlaşma, paylaşma, iyilikseverlik gibi kültürümüzün temel değerleri de komşuluk ilişkileri içerisinde yer almıştır. İncelenen şarkılarda komşuluk kültürüne de vurgu

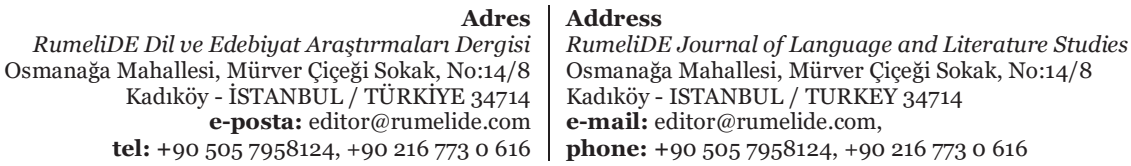


yapılmıştır. Küreselleşme, dijitalleşme ve yoğun çalışmanın neticesinde ortaya çıkan bireyselleşme ne kadar komşuluk ilişkilerini yıpratsa da Türk kültüründe komşuluk ilişkileri devamlılığını sürdürmektedir. Çizgi filmde yer alan "Turşu Turşu” adlı şarkıda kış hazırlıklarından biri olan turşu hazırlama için komşunun davet edilmesi, imece usulü kış hazırlıklarını hatırlatmaktadır: "Komşu komşu komşu komşu / Komşu komşu komşu komşu / Hadi gel gidelim pazara komşu / Alalım lahana kuralım turşu / Turşu turşu turşu turşu / Turşu turşu turşu turşu / Gel otur yanıma yiyelim turşu / Sonra da suyunu içelim komşu." Komşu ile birlikte turşu kurma ve turşu suyu içme sahneleri şarkının klibinde de yer alır. Buna göre Tinky ve Minky komşudur. Birlikte pazara gidip turşuluk malzeme alırlar ve evde turşu kurarlar. Sonra da birlikte yiyip suyunu içerler. Görüldüğü gibi şarkının sözlerinde ve klibinde komşuluk kültürüne ait bir aktarım söz konusudur.

\subsection{Pazar kültürü}

“Turşu Turşu” adlı şarkıda pazar kültürünün öne çıktığı görülmektedir. Birbirine komşu olan Tinky ve Minky turşu kuracak malzemeyi almak için pazara gider. Şarkı sözünde de bu yer alır: "Komşu komşu komşu komşu / Hadi gel gidelim pazara komşu / Alalım lahana kuralım turşu.” Şarkının klibinde pazar ortamı canlı bir şekilde gösterilmektedir. İki komşu olan Tinky ve Minky ile birlikte Kukuli de pazarın yolunu tutar. Kukulinin elinde pazar arabası vardır. Tinky ve Minky de pazar çantalarını almıştır. Üçü tezgâhları dolaşıp uygun fiyatı bulmaya çalışırken esnaf onları kendi tezgâhına çekmek için uğraşır. Sonunda bir tezgâha yaklaşıp lahana alırlar. Lahananın elden ele atılarak verildiği görülür. Tezgâhtaki pazarcı çevik hareketlerle kocaman lahanayı bir anda poşetin içine koyar. Pazar kültürüne dair bu aktarım da tektiplemiş ve zincir marketlerin elinde ilerleyen alışveriş anlayışının yaygınlaştığı günümüzde geleneksel esnaf ve pazar kültürünün çocuklar tarafından bilinmesini sağlayacaktır.

\subsection{Paylaşımcılık}

Türk kültüründe paylaşmanın önemli bir yeri vardır. Paylaşmak; toplumun fertlerini birbirine bağlar, birlik ve beraberliğin pekişmesini sağlayan bir yönü vardır. Atasözleri ve deyimlerimizde yer alan "Biri yer, biri bakar; kıyamet ondan kopar. (Aksoy, 1993: 90)", "Komşuda pişer, bize de düşer(Aksoy 1993: 167). "göz hakkı" gibi ifadeler ve bir hadis olan, milletimizce özümsenip atasözü gibi dillerde dolaşan "Komşusu aç iken tok yatan bizden değildir." ifadeleri Türk toplumunun paylaşmaya verdiği önemi göstermektedir. Kukuli adlı çizgi filmin şarkılarında da paylaşma kültürüne yer verilmiştir. İncelenen diğer şarkıların kliplerinde ve sözlerinde küçük göndermeler bulunmakla birlikte paylaşma kültürünü tam olarak yansıtan şarkı "Paylaşmak Güzel” adlı şarkıdır. Bu şarkının hem sözlerinde hem klibinde paylaşmanın teşvik edildiği görülmektedir: "Hey Kukuli merhaba! / Nasılsın, iyi misin? / Bir sürprizim var sana hadi yine iyisin! / Çikolata çok tatlı ama paylaşmak daha tatlı / Bir sana bir de bana yapalım kardeş payı / Paylaşmak güzel paylaşmak güzel / Haydi sen de gel paylaşmak güzel / Paylaşmak güzel (hey) paylaşmak güzel.” Şarkının devamında geçen ve bugün annelerimizin kalıp sözü haline gelen "Acık da kardeşe ver” ifadesi de paylaşma kültürünün günlük hayata kattığı güzel söylemlerden birisidir. Yine halk arasında söylenen "Bir kişinin doyduğu ile iki kişi de doyar” sözü şarkıda şu şekilde yer almaktadır: "Bir kişi doyuyorsa iki kişi de doyar / İki kişi doyarsa üçüncüye de yer var / Üç kişilik bir yemek dördüncüye de yeter / Sofrada var dört kişi, davet et beşinciyi / Paylaşmak güzel paylaşmak güzel / Haydi sen de gel paylaşmak güzel.” Şarkının klibinde de çizgi film kahramanları yiyeceklerini birbiriyle paylaşır ve paylaştıkça mutlu olur. Ayrıca klibin son sahnesinde Tinky, Minky ve Kukuli ellerinde paylaşımı teşvik eden sözler içeren pankartlar taşır. Bu pankartların üzerinde "Kendin pişir kendin ye! Birlikte yiyelim!", "Paylaştığın senindir, biriktirdiğin değil!”, "Yemeğinin resmini değil yemeğini paylaş!”

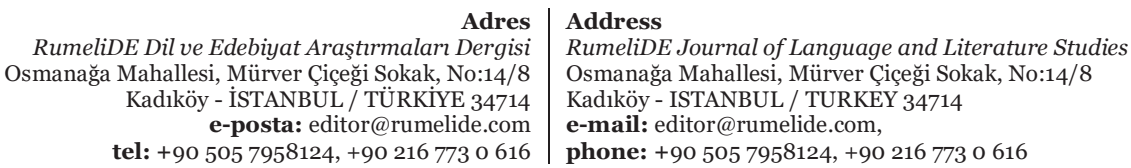


yazmaktadır. Şarkının sözleri ve klibi Türk kültürünün önemli bir değeri olan paylaşımcllı̆̆ı çocuklara sevdirip benimsetmesi açısından dikkate deerdir.

\subsection{Aile}

Aile toplumun en küçük yapılanmasıdır ve ailenin temelinin sağlam olması toplumun sağlam temellerde yükselmesi anlamına gelmektedir. Türk toplumunun yapılanmasında sağlam bir aile düzeni vardır( Kağıtç̧ıaşı 1990: 13). İncelenen şarkılarda Türk aile ortamına yönelik unsurlar da yer almaktadır. "Anne Ner'de" adlı şarkıda Türk aile yapısı içerisinde anne ve çocuk arasında sıkça geçen bir diyaloğa yer verilmektedir: "Anne çorabım nerede? / Nereye koyduysan ordadır. / Anne pijamalarım? / Nereye koyduysan ordadır. / Sağa baktım sola baktım bulamadım / Nereye koyduysan ordadır. / Evin altını üstüne getirdim / / Nereye koyduysan ordadır.” Eşyalarını kaybeden çocuklar, annesine giderek eşyalarının nerede olduğunu sorar. Annesi de o kalıp sözü söyler: "Nereye koyduysan ordadır." Bu şarkıda ve klibinde aile ortamında çocuk eğitimi huşuna yer verilmiştir.

"Akşam Yatmaz Sabah Kalmaz" adlı şarkıda da yine anne-çocuk ilişkisine yer verilir. Televizyon ve bilgisayar başında vakit geçirip yatmayan çocuğa annesi kızar ve çocuk annesinin sözünü dinlemediği için sonunda terliği yer: "Saat olmuş on bir, on iki / Hala ayakta bizimki / Büyük sözü dinlemez ki / Terliği yer annesinden." Burada biraz da mizahi bir yaklaşımla ile anne ile çocuk arasındaki irtibat ele alınmıştır. Annelerin çocuklarına sözlerini dinletmek için terlik firlatması (Terlik çocuğa isabet ettirilmez, çocuğa kıyamayan anne terliği bilerek onun yanına doğru atar. Bu durum "terlik geliyor" gibi kalıplaşmış bir sözü ortaya çıkarmıştır.) durumu şarkı sözlerinde ele alınmıştır.

\subsection{Dijitalleşme}

Günümüzde geleneksel kültürü etkileyen en önemli faktörlerden biri dijitalleşmedir. Teknolojinin gelişimi ile birlikte hayatımıza giren televizyon ve bilgisayar günlük yaşamı da olumlu ve olumsuz etkilemeye başlamıştır. Bu etki somut olmayan kültürel mirasa ait unsurların da değişim ve dönüşümüne hatta bazen yok olmasına neden olmaktadır. Bu sebeple makalede modern kültürü şekillendiren, somut olmayan kültür unsurlarını da etkileyen dijitalleşmeye yer verilmiştir.

Toplumsal hayattaki dijitalleşme durumu Kukuli adlı çizgi filmde de ele alınmıştır. "Akşam Yatmaz Sabah Kalmaz" adlı şarkıda dijitalleşmenin olumsuz yönüne vurgu yapılmaktadır: "Televizyonun karşısında / Bilgisayarın başında / Oyun oynar saatlerce / Gezer durur internette / Akşam yatmaz sabah kalkmaz / Uykusunu alamaz / Akşam yatmaz sabah kalkmaz / Seni gidi yaramaz”. Geleneksel kültüre göre erken yatıp erken kalkılmaktadır. Televizyon, bilgisayar ve internetin hayatımıza girmesi ile birlikte bu düzen bozulur. Kültür içindeki bu değişime işaret etmesi bakımından bu şarkı önemlidir.

\subsection{Kentleşme ve kültür değişimi}

Kentleşme ve kent yaşamının doğal bir getirisi olan kültür değişimi somut olmayan kültür unsurlarını da olumlu / olumsuz yönlerden etkilemiş̧ir. Yaşam tarzının değişmesi bazı kültür unsurlarının da değişimini, dönüşümünü sağlamıştır. Bu değişimler bazen maalesef kültürü yozlaşmaya kadar götürmüş hatta kültüre ait bazı unsurların tamamen ortadan kalkmasına yol açmıştır. Burada kentleşme ve kültür değişimi başlığının açılmasının nedeni kentleşmenin kültür değişimine neden olması bu durumun da somut olmayan kültürel mirası doğrudan etkilemesidir.

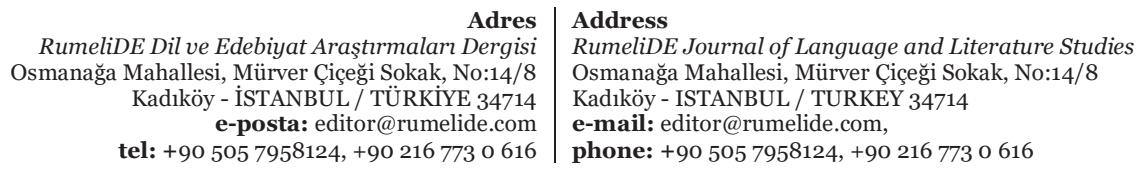


Kentleşme / kültür değişimi ile ilgili vurgu ise Barış Mançoya ait olan ve film içerisine yerleştirilen "Arkadaşım Eşek" adlı şarkıda yer alır. Şarkının sözlerine uygun olarak klipte Kukuli yıllar önce göç ettiği köyünü ve en yakın arkadaşı eşeği özler. Şehirde evin içinde, doğadan uzak bir yaşamı olan Kukuli, sıkılır ve fotoğraf albümünü eline alır. Fotoğraflara bakarak arkadaşı eşek ile köyde geçirdiği güzel anları hatırlar. "Kaç yıl oldu saymadım köyden göçeli / Mevsimler geldi geçti, görüşmeyeli / Hiç haber göndermedin o günden beri / Yoksa bana küstün mü? Unuttun mu beni? / Dün yine seni andım, gözlerim doldu / O tatl günlerimiz bir anı oldu / Ayrıllk geldi başa, katlanmak gerek / Seni çok çok özledim, arkadaşım eşek." Kukuli geride bıraktığı hayatı, doğa ile iç içe olmayı özlemiştir. Çayırda tepişen yaban tayları, kedilerle dövüşen çilli horoz, Sarıkız ve buzağıSı, kuzular ve oğlaklar Kukuli'nin gözünde canlanır ve o günlere olan özlemi artar: "Yaban tayları çayırda tepişiyor mu? / Çilli horoz kedilerle dövüşüyor mu? / Sarıkız minik buzağıyı sütten kesti mi? /Kuzularla oğlaklar sevişiyor mu?” Sonunda Tinky ve Minky onu köye götürmeye karar verir. Hepsi valizleri hazırlayıp Dütdüt'e binerek köye gider. Kukuli, arkadaşı eşeğe ve köyüne kavuşup mutlu olur. Bu şarkıda ve klibinde kültür değişimi, köyden kente göç ve köy özlemi konuları öne çıkmıştır. Özellikle kentte, köy ortamından uzak yaşayan çocuklar için köy hayatı hakkında fikir vermesi, köy kültürünün aktarımı açısından bu şarkı ve çizgi filmdeki klibi dikkate değerdir.

\section{Sonuç}

İnsanoğlu geçmişten günümüze çeşitli araçlarla iletişim kurmuş ve şekillendirdiği kültürü gelecek kuşaklara bu iletişim araçları yardımıyla aktarmıştır. Günümüzde bu iletişim araçlarından en yaygın olanı televizyon ve internettir. Çekirdek ailelerin yaygınlaştığı, çeşitli nedenlerden dolayı nine ve dededen uzak yaşamın geliştiği, anne babanın ise yoğun çalışma temposundan dolayı çocukla geçirdiği sürenin azaldığı günümüzde çocuklar zihinsel açıdan çoğunlukla televizyon ve internetten beslenmektedir. Kültürümüze ait kodların çocuklara aktarılması hususundaki görev de büyük ölçüde yine televizyon ve internete düşmektedir. Bu bakımdan çocukların izlediği çizgi filmlerin içeriğinde kültürel unsurların yer alması, çizgi film aracılığı ile kültürel değerlerimizin gelecek kuşaklara aktarılması önem arz etmektedir. Bu bağlamda burada Kukuli adlı çizgi filmde yer alan şarkı / türküler ve bu şarkıların klipleri kültürel unsur içermeleri bakımından değerlendirilmiştir. Şarkılarda ve kliplerinde Türk kültürüne ait temel değerlerin, somut olmayan kültürel miras ögelerinin işlendiği tespit edilmiştir. Kültürü oluşturan ve geliştiren en önemli unsur olan dilin kalıplaşmış ifadelerine şarkı /türkü sözlerinde sıklıkla yer verildiği görülmüştür. Ayrıca halk dansları, müzik kültürü, halk mutfă̆ı, halk hekimliği, temizlik, aile kültürü, komşuluk kültürü, paylaşımcılık, meslek folkloru, pazar kültürü tespit edilen kültürel unsurlar arasındadır. Somut olmayan kültürel miras unsurlarını önemli ölçüde etkileyen, değiştirip dönüştüren modern çağın getirdiği dijital kültür ve şehirlileşme/kültür değişimi gibi konular da incelenen şarkı /türkü ve kliplerde yer almaktadır.

Türk halk kültürüne dair bu unsurların dijital ortama taşınması, çizgi filmle ve şarkı içerisinde sunumu, kültürün gelecek kuşaklara aktarımında etkili bir araçtır. Bu sebeple içerisinde Türk kültürüne ait unsurları barındıran çizgi film sayısının artması kültürün yinelenerek ve yenilenerek aktarımını kolaylaştıracak, somut olmayan kültürel unsurların yaşatılarak korunmasını sağlayacaktır.

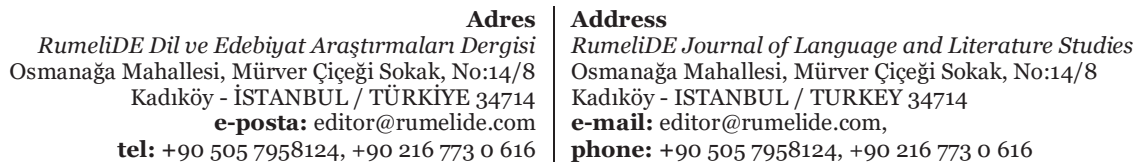
tel: $+905057958124+902167730616$ 


\section{Kaynakça}

Ahunbay, Zeynep vd. (2018). Kültür Mirası ve Komşuluk İlişkileri. İstanbul Albatros Yayınları.

Aksoy, Ö. Asım (1993). Atasözleri ve Deyimler Sözlüğ̈̈. İstanbul: İnkılap Kitabevi.

Alan, İlkay (2009). Sevgi İçerikli Çizgi Filmlerin İlköğretim 5. Sinıftaki Çocukların Görsel Sanatlar Dersinde Yaptıkları Resimler Üzerindeki Etkisinin İncelenmesi. Yayımlanmamış Yüksek Lisans Tezi, Ankara: Gazi Üniversitesi.

Atan, Uğur. (1995). Animasyonun Kültür Aktarımındaki Yeri. Yayımlanmamış Yüksek Lisans Tezi, Konya: Selçuk Üniversitesi.

Boratav, P. Naili (1997). 100 Soruda Türk Folkloru. İstanbul: Gerçek Yayınevi.

Eskandari, Maryam (2007). İran'da TV'de Yayınlanan Çizgi Filmlerin İlkokul Öğrencilerinin Eğitimine Etkisi. Yayımlanmamış Yüksek Lisans Tezi. Ankara: Gazi Üniversitesi.

Eşitti, Şakir (2016). Çizgi Filmlerde Küresel Ve Yerel Kültürün İnşası: Caillou Ve Pepee Örneği. Karadeniz Uluslararası Bilimsel Dergi. 32, 125-144.

Gürçayır, Selcan (2011). Somut Olmayan Kültürel Mirasın Korunması Sözleşmesi Üzerine Eleştirel Bir Okuma. Millî Folklor. 92, 5-10.

https://tr.10steps.org/Fazer-Maracas-2614 (29.12.2021).

https://www.youtube.com/channel/UCF5IUvgXe_3sHBuKpEz7Btw (02.01.2022).

http://www.animasyongastesi.com/tag/kukuli/(05.01.2022).

http://www.ranini.tv/haber/31721/1/yerli-cizgi-dizi-kukulinin-sohreti-gunden-gune-buyumeyedevam-ediyor (05.01.2022).

Kaba, Fethi (1992). Animasyonun Eğitim Amaçl Kullanımı. Yayımlanmamış Yüksek Lisans Tezi. Eskişehir: Anadolu Üniversitesi.

Kağıtçıbaşı, Çiğdem (1990). İnsan Aile Kültürr. İstanbul: Remzi Kitabevi.

Kılcı, Şule. (2009). Tüketim Toplumunun Bir Formu Olarak Çizgi Filmlerde Çocukluk ve Toplumsal Cinsiyet Temsilleri: Barbie, Bratz ve Winx Clup. Yayımlanmamış Yüksek Lisans Tezi. Kocaeli: Kocaeli Üniversitesi.

Metin Basat, Ezgi (2014). Sözden Çizgiye: Karikatüristlerin Gözünden Sözlü Anlatılar. Millî Folklor, 101, 226-227.

Muratoğlu, Bahar (2009). Sosyal Sapkinhğın Medyadaki Temsilinin Çizgi Filmler Üzerinden İncelenmesi. Yayımlanmamış Yüksek Lisans Tezi, İstanbul: İstanbul Üniversitesi.

Oğuz, M. Öcal (2009). Somut Olmayan Kültürel Miras Nedir? Ankara: Geleneksel Yayıncllı.

Oğuz, M. Öcal (2013 ). Terim Olarak Somut Olmayan Kültürel Miras. Millî Folklor, 100, 5-13.

Ölçer Özünel, Evrim (2012). Kırkyama Kahramanlar: Tarihi Çizgi Romanlarda Gelenek İcadı ve İmhası. Millî Folklor, 95, 170-174.

Özakçaoğlu, Nilüfer (2009). Çizgi Filmlerin Eğitilebilir Zihinsel Engelli Öğrencilerin Resimlerine Anlatım, Biçim ve Renk Olarak Yansıması. Yayımlanmamış Yüksek Lisans Tezi, Ankara: Gazi Üniversitesi.

Özsevgeç Cerrah, Lale ve Saka, Arzu (2018). Çocukların İzledikleri Çizgi Filmler ve Bu tercihlerinin Karakterleri ile İlişkisi.

Türkmen, Nilgün (2012). Çizgi Filmlerin Kültür Aktarımındaki Rolü ve Pepee. Cumhuriyet Üniversitesi Sosyal Bilimler Dergisi, 36/2,145-148.

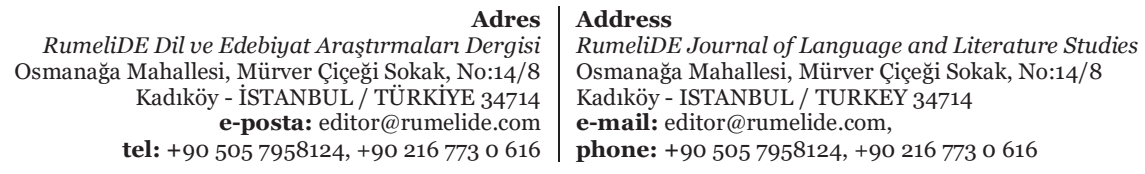

